\title{
External Location of the Buccinator Muscle to Facilitate Electromyographic Analysis
}

\author{
Regina Helena Barbosa TAVARES DA SILVA ${ }^{1}$ \\ Hélio Ferraz PORCIÚNCULA ${ }^{2}$ \\ Renata Savastano Ribeiro JARDINI ${ }^{3}$ \\ Ana Paula Gonçalves PITA ${ }^{1}$ \\ Ana Paula Dias RIBEIRO ${ }^{1}$ \\ ${ }^{1}$ Department of Dental Materials and Prosthodontics, Dental School of Araraquara, \\ São Paulo State University, Araraquara, SP, Brazil \\ ${ }^{2}$ Department of Morphology, Dental School of Araraquara, São Paulo State University, Araraquara, SP, Brazil \\ ${ }^{3}$ Speech Therapist, Medical School of São Paulo, Federal University of São Paulo, São Paulo, SP, Brazil
}

\begin{abstract}
Electromyography is frequently used to measure the activity of masticatory muscles. It requires the precise setting of the electrodes, which demands the accurate location of the muscle to be evaluated. The purpose of this study was to investigate the accuracy of an external method to locate the buccinator muscle. Fifteen human cadavers were evaluated and planes were determined on the face using anatomic landmarks. An angle $(\alpha)$ was obtained at the intersection of these planes on the central point of buccinator muscle and measured with a protractor. The value of the angle allows locating the central point of buccinator muscle based on anatomic landmarks on the face. Statistical analysis of the collected data indicated an angle of $90^{\circ}$ with $95 \%$ reliability, thus proving the efficacy of the proposed method.
\end{abstract}

Key Words: facial muscles, buccinator muscle, electromyography.

\section{INTRODUCTION}

The buccinator muscle is a plain, square-shaped bilateral mimic muscle, which composes the mobile and adaptable portion of the cheek. It is frequently referred to as an accessory muscle of mastication because of its role on chewing food and swallowing and compressing the cheeks against the molars, as well as its use for whistling, sucking and blowing. The buccinator muscle gradually contracts during mouth closing and relaxes during mouth opening, maintaining the required tension of the cheeks, in order to avoid biting on the jugal mucosa $(1,2)$.

This muscle has different origins: the pterygomandibular raphe and the buccal alveolar bone of maxillary and mandibular molars. First, it originates from a fibrous bundle (the pterygomandibular raphe), which runs from the pterygoid hamulus on the inferior portion of the medial surface of the mandible close to the posterior portion of the mylohyoid line. The pterygomandibular raphe connects the anterior portion of the superior constrictor muscle of the pharynx with the posterior portion of the buccinator $(1,2)$. From the two bone origins (buccal alveolar bone of maxillary and mandibular molars) and from the pterygomandibular raphe, the fibers of the buccinator muscle run anteriorly, forming the musculature of the cheek. They blend with the fibers of the orbicularis oris at the corners of the mouth (Fig. 1). While its central fibers run ahead, its upper fibers and the lower fibers join the fibers of the orbicular muscle of mouth in the lower lip and upper lip, respectively. Buccinator innervation comes from both portions of the facial (7th pair of cranial nerves), temporofacial and cervicofacial nerves (1-3).

In some individuals, the facial muscles, including the chewing muscles, present parafunctional activities 
in addition to the normal functional action. Unlike the functional activities, the parafunctional ones are not controlled and cause damage to the adjacent structures (4). Bruxism is a well known parafunctional habit defined as the non-functional dental contact characterized by grinding and/or clenching of teeth (5) during sleep or while awake (4). The actual causes of these disturbances have not yet been clarified, but parafunction is believed to have occlusal, psychological and/or central nervous system origins $(4,6,7)$.

Individuals with bruxism presents increased electrical activity of the chewing musculature (buccinator, temporomandibular, masseter and pterygoid muscles) (8), and thus a possible indirect involvement of the buccinator muscle in parafunctional habits has been suggested (7). Numerous studies relating to facial expression, pronunciation, swallowing, sucking, blowing, mandibular movements and mastication have been conducted with the buccinator muscle (9). However, there are no studies proving the electrical activity alterations of the buccinator muscle during the occurrence of these habits.

Electromyography (EMG) is the study of mus-

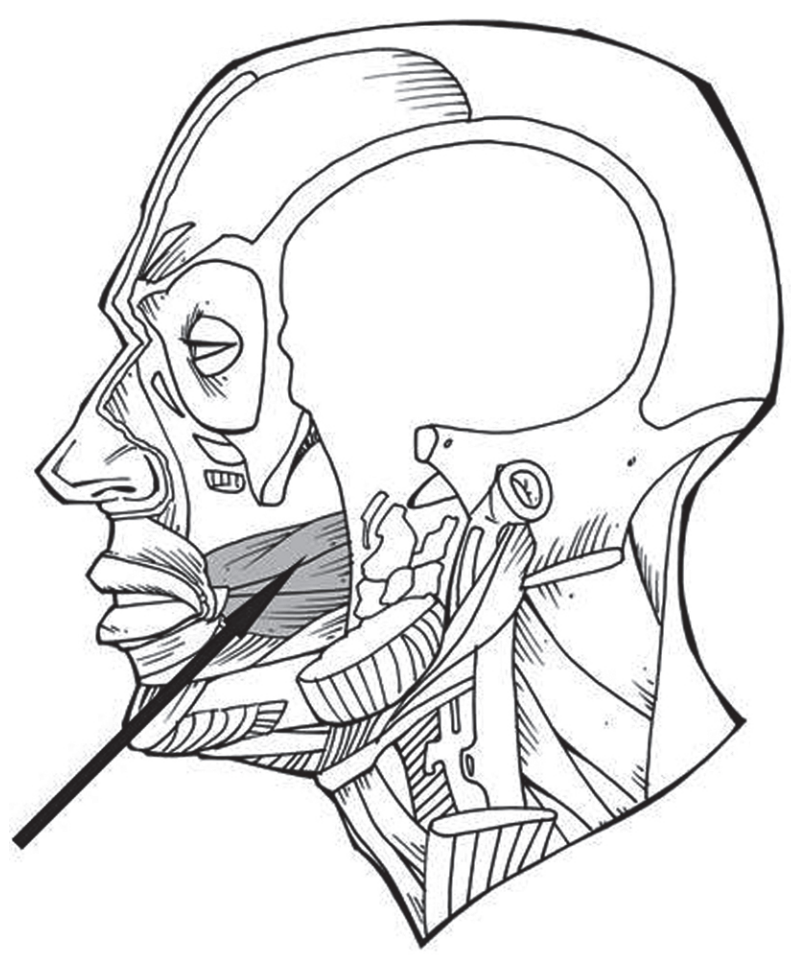

Figure 1. Buccinator muscle. cular function by recording electrical signs propagated in the muscles (10). These records are done by accurately placing electrodes at the exact point corresponding to the external location of the muscle whose electrical activity should be measured. EMG analysis is currently a practical and efficient method to detect the occurrence of alterations in the electrical activity of muscles involved in parafunctional habits.

The aim of this study was to investigate the accuracy of an external method to locate the buccinator muscle using landmarks.

\section{MATERIAL AND METHODS}

Fifteen formalin-fixed adult human cadaver heads belonging to the Department of Morphology, Dental School of Araraquara, São Paulo State University, Brazil, were used in this study.

Three landmarks were first determined in a hemiface (Fig. 1): Point A: eye external angle; Point B: labial angle; Point $\mathrm{C}$ : external point corresponding to the central point of buccinator muscle. Points A and B (Fig. 2) were easily demarcated by positioning pins on the

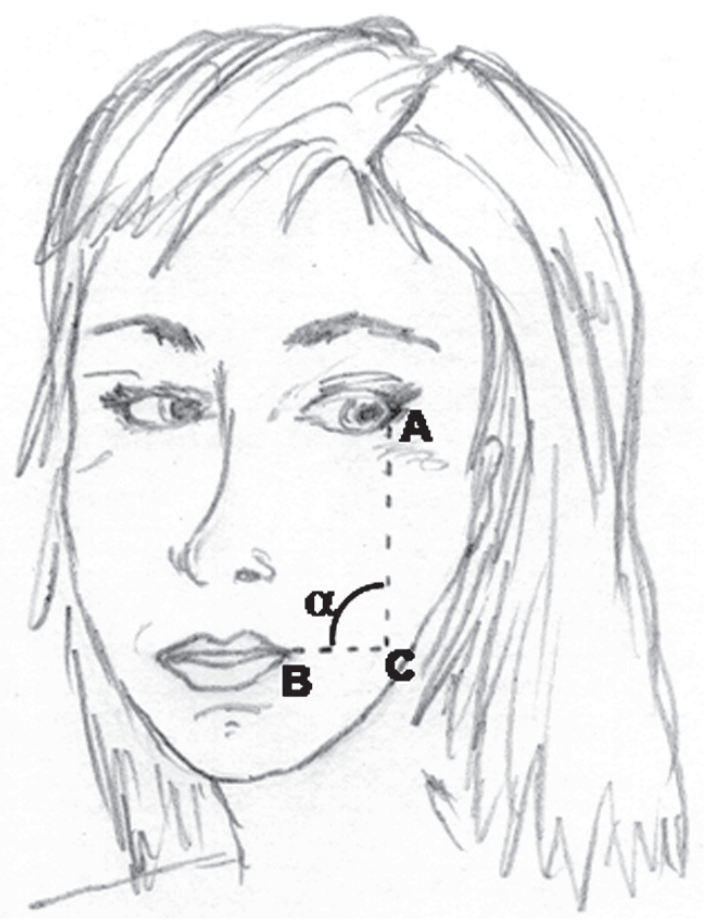

Figure 2. Schematic drawing showing the 3 landmarks (A, B and C) demarcated on a hemi-face for location of the buccinator muscle. 
respective anatomic landmarks. The $\mathrm{C}$ point was demarcated (Fig. 2) by the inner location of the central point of buccinator muscle by means of skin detachment for external pin fixation.

Two planes were determined: AC plane: vertical plane that passes simultaneously through points $\mathrm{A}$ and $\mathrm{C}$, with the operator at $45^{\circ}$ in relation to the sagital plane of the anatomic specimen; BC plane: horizontal plane, that passes simultaneously through points B and C. An angle was obtained at the intersection of these planes ( $\alpha$ angle; Fig. 2), measured with a protractor and its values were tabulated for further statistical analysis. Data were analyzed statistically by ANOVA and Tukey test at 5\% significance level.

\section{RESULTS}

Table 1 presents the $\alpha$ angle values obtained at the intersection of planes $\mathrm{AC}$ and $\mathrm{BC}$, according to the proposed methodology. The average of the $\alpha$ angle values was $90.33^{\circ}$ with a standard deviation of $5.30^{\circ}$. The confidence interval for the average is defined by the upper and lower limits, depending on both the t value (tabulated and varying with the number of observations) and the average standard error, which, in this case, was $1.37^{\circ}$. While the standard deviation is a measure of original data variability, the standard error is a measure of the average distribution variability.

So, in this study, the angle value obtained from data was $90.33^{\circ} \pm 5.30^{\circ}$ and the confidence interval for the average was $90.33^{\circ} \pm 2.96^{\circ}$, for observations with $95 \%$ confidence level. This means that the researcher deposits a reliability of $95 \%$ that the average value of the angle at issue in an unknown population was in the $93.29^{\circ}$ to $87.37^{\circ}$ range. Therefore, with a reliability level of $95 \%$, the angle was considered as being of $90^{\circ}(13)$.

\section{DISCUSSION}

The position of the electrodes for EMG studies of the buccinator muscle used to be determined by the position of certain teeth, such as the second molar (11) and the first molar (12). This technique, however, is limited because the teeth used as a reference can be in different positions or can even be absent.
Hanawa et al. (9), in a recent study, used electrode location techniques based on the activity of the central site of the cheek. They evaluated the EMG activity recorded from the anterior, central and posterior sites of the cheek. The anterior and posterior sites had interference from other muscles, and the central site showed a remarkable activity when laughing and contaminations of the action potential of other muscles were not observed (9).

The location method proposed in the present study, which is based on external facial points, was proved effective by the statistical analysis. The tested method accurately located the central point of the buccinator muscle, which allows a precise positioning of the electrodes for EMG analysis. The findings of this experiment showed that the use of anatomic facial landmarks allowed determining the exact point for electrode positioning with $95 \%$ degree of reliability. The proposed method offers a simple and non-invasive technique to locate the buccinator muscle for placement of surface electrodes in EMG studies.
Table 1. Angle $(\alpha)$ obtained at the intersection of planes AC and BC in each anatomic specimen, according to the proposed methodology.

Angle $\quad 87^{\circ} 91^{\circ} 92^{\circ} 93^{\circ} 95^{\circ} 86^{\circ} 84^{\circ} 90^{\circ} 88^{\circ} 85^{\circ} 99^{\circ} 84^{\circ} 102^{\circ} 91^{\circ} 88^{\circ}$

\section{RESUMO}

A eletromiografia é frequentemente utilizada para mensurar a atividade dos músculos mastigatórios. Esta análise exige a colocação precisa dos eletrodos, o que requer a localização exata do músculo a ser avaliado. O objetivo do presente estudo foi investigar a acurácia de um método externo para localização do músculo bucinador. Quinze cadáveres humanos foram avaliados e planos foram determinados na face utilizando-se pontos de referência anatômicos. Um ângulo $(\alpha)$ foi obtido na interseção desses planos no ponto central do músculo bucinador e foi medido com um transferidor. O valor do ângulo permite localizar o ponto central do músculo bucinador baseado nos pontos de referência anatômicos da face. A análise estatística dos dados obtidos indicou um ângulo de $90^{\circ} \mathrm{com} 95 \%$ de confiabilidade, confirmando dessa forma a eficácia do método proposto. 


\section{ACKNOWLEDGEMENTS}

The authors would like to thank Dr. Lydia S. R. Ruiz for the statistical analysis and Mr. Marcelo Brito Conte for his technical assistance at the Laboratory of Anatomy of the School of Dentistry of Araraquara, São Paulo State University, Brazil.

\section{REFERENCES}

1. D'Andrea E, Barbaix E. Anatomic research on the perioral muscles, functional matrix of the maxillary and mandibular bones. Surg Radiol Anat 2006;28:261-266.

2. Plas E, Deliac P, Garuet Lempirou A, Caix P, Bioulac B. The buccinator muscle: an original morphogenetical study. Morphologie 2004;88:27-30.

3. Vitti M, Basmajian JV, Ouellette PL, Mitchell DL, Eastmen WP, Seaborn RD. Electromyographic investigations of the tongue and circumoral muscular sling with fine-wire electrodes. J Dent Res 1975;54:844-849.

4. Takemura T, Takahashi T, Fukuda M, Ohnuki T, Asunuma T, Masuda $\mathrm{Y}$ et al.. A psychological study on patients with masticatory muscle disorder and sleep bruxism. Cranio 2006;24:191-196.
5. Pierce CJ, Chrisman K, Bennett ME, Close JM. Stress, anticipatory stress, and psychologic measures related to sleep bruxism. J Orofac Pain 1995;9:51-56.

6. Koyano K, Tsukiyama Y, Ichiki R. Local factors associated with parafunction and prosthodontics. Int $\mathrm{J}$ Prosthodont 2005;18:293-294.

7. Trenouth MJ. Undefined relationships. $\mathrm{Br}$ Dent J 2007;202:644.

8. Ahlgren J. EMG studies of lip and cheek activity in sucking habits. Swed Dent J 1995;19:95-101.

9. Hanawa S, Tsuboi A, Watanabe M, Sasaki K. EMG study for perioral facial muscles function during mastication. J Oral Rehab 2008;35:159-170.

10. Basmajian JV, Luca LJ. Muscles Alive: their functions revealed by electromyography. 5th ed. Baltimore: Willians \& Wilkins; 1985.

11. Basmajian JV, Newton WJ. Feedback training of parts of buccinator muscle in man. Psychophysiol 1974;11:92-92.

12. Lundquist DO. An electromyographic analysis of the function of the buccinator muscle as an aid to denture retention and stabilization. J Prosthet Dent 1959;9:44-52.

Accepted March 17, 2008 